
\title{
IL-18 gene polymorphisms were associated with risk of chronic obstructive pulmonary disease in a Chinese Han population
}

\author{
Chongya Huang ${ }^{1}$, Lijun Mei ${ }^{2}$, Ajing Wang ${ }^{3}$ and Xian Zhang ${ }^{4}$ \\ ${ }^{1}$ School of Medicine, Xi'an Jiaotong University, Xi'an, Shaanxi 710061, China \\ ${ }^{2}$ Department of Blood Transfusion, Ankang Central Hosipital, Ankang, Shaanxi 725000, China \\ ${ }^{3}$ Department of Outpatient, The First Affiliated Hospital of Xi'an Jiaotong University, Xi'an, Shaanxi 710061, China \\ ${ }^{4}$ Department of Clinic Laboratory, Xi'an Hospital of Traditional Chinese Medicine, Xi'an, Shaanxi 710021, China \\ Correspondence to: Xian Zhang, email: xianzhangMD@163.com \\ Keywords: chronic obstructive pulmonary disease (COPD); IL18; single nucleotide polymorphism (SNPS); case-control study \\ Received: November 09, $2017 \quad$ Accepted: December 06, $2017 \quad$ Published: January 02, 2018 \\ Copyright: Huang et al. This is an open-access article distributed under the terms of the Creative Commons Attribution License \\ 3.0 (CC BY 3.0), which permits unrestricted use, distribution, and reproduction in any medium, provided the original author and \\ source are credited.
}

\section{ABSTRACT}

Chronic obstructive pulmonary disease (COPD) is a kind of lung disease with high morbidity and mortality. Genetic polymorphisms of IL18 have been associated with respiratory system disease such as asthma, pulmonary tuberculosis, and lung cancer; however, little information is found about the association between IL18 polymorphisms and risk of COPD. We investigated the association between single nucleotide polymorphisms (SNPS) in IL18 and COPD risk in a case-control study that included 300 COPD cases and $\mathbf{3 0 0}$ healthy controls. Five SNPs were selected and genotyped using the Sequenom MassARRAY platform. Odds ratios (ORs) and $\mathbf{9 5 \%}$ confidence intervals (CIs) were calculated using unconditional logistic regression after adjusting for gender and age. In the genotype model analysis, we determined that rs2043055 polymorphism had an increased effect on the risk of COPD (GG versus $A A: O R=5.29 ; 95 \% C I=1.15-24.35 ; p=0.006)$. In the genetic model analysis, we identified four SNPs associated with COPD risk under recessive model. The "GG" genotype of rs2043055 and rs187238 were associated with increased risk of COPD (rs2043055: OR = 5.13, 95\% CI = 1.12-23.49, $p=0.021 ;$ rs187238: OR $=4.99,95 \% \mathrm{CI}$ $=1.08-23.06, p=0.025)$. Additionally, the "CC" genotype of rs 1946519 was associated with increased risk of COPD $(O R=2.31 ; 95 \% C I=1.03-5.19 ; p=0.038)$. By contrast, the "TT" genotype of rs1946518 was associated with decreased risk of COPD (OR = $0.58 ; 95 \% \mathrm{CI}=0.35-0.98 ; p=0.039$ ). Our data shed new light on the association between IL18 polymorphisms and risk of COPD in a Chinese Han population.

\section{INTRODUCTION}

In recent years, with the developing of industry and worsening of air condition, more and more people suffer from chronic respiratory disease. Chronic obstructive pulmonary disease (COPD) is a type of chronic respiratory disease with high morbidity and mortality. In clinical medicine, COPD is distinguished by chronic airflow limitation, which mainly caused by local inflammation of the respiratory system and systemic inflammatory [1]. Epidemiologic studies pointed out that smoking is an important environmental risk factor for COPD, whereas only a fraction of smokers eventually developed to COPD [2]. COPD is a complicated disease which influenced by multiple genes and interaction with environmental factors [3]. Previous literatures have identified several susceptibility genes contribute to the development of COPD, including SCGB1A1, CHRNA5, VEGF-A, FAM13A, SETD7 and so on [4-6]. However, this is not enough to explain the hereditary susceptibility of COPD. Researchers still concentrate on work on identifying more susceptibility genes for this disease. 
Interleukin-18 (IL-18), also known as interferon (IFN) $-\gamma$ inducing factor, belongs to the IL-1 cytokine superfamily [7]. IL-18 is a pro-inflammatory cytokine which could modulates the $\mathrm{Th} 1 / \mathrm{Th} 2$ response together with other factors [8], and further activates innate immunity and inflammatory response in human body [9]. Previous studies have identified a lot of single nucleotide polymorphism (SNPs) in IL18 gene associated with several disease. For example, rs187238 and rs1946518, in the promoter of the $I L 18$, have close correlation with a wide range of disease in different populations, including multiple sclerosis, Crohn's disease, pulmonary tuberculosis, asthma, hepatitis B virus-related cirrhosis, breast, lung and liver cancer [10-16]. To date, genetic polymorphisms of $I L 18$ have been associated with respiratory system disease such as asthma, pulmonary tuberculosis, and lung cancer; however, the correlation between IL18 polymorphisms and risk of COPD is still unclear.

In this study, we selected five SNPs in IL18: rs2043055, rs187238, rs1946518, rs1946519 and rs5744224, and investigated their association with COPD risk in a Chinese Han population.

\section{RESULTS}

A total of 300 COPD patients and 300 healthy controls were recruited in the study. The distribution of gender, age and smoking status of the patient and control groups are described in Table 1 The basic characteristics of patient and control groups are well matched $(p>0.05)$.

All SNP call rates exceeded $98.0 \%$, which was considered high enough to perform association analyses. The basic information of the IL18 polymorphisms (rs2043055, rs187238, rs1946518, rs1946519 and rs5744224) are listed in Table 2, including gene, band, position, alleles and minor allele frequency (MAF). All SNPs accord with HardyWeinberg equilibrium (HWE) in the controls $(p>0.05)$. No significant differences were observed in the MAFs of SNPs between COPD patients and healthy controls.

The genotypes frequencies of the IL18SNPs and their associations with risk of COPD are shown in Table 3. Notably, for rs2043055, compared with the AA genotype, the frequency of GG genotype was significantly different between cases and controls (GG versus AA: OR = 5.29; $95 \% \mathrm{CI}=1.15-24.35 ; p=0.006)$, which suggested that the GG genotype of rs2043055 may be a risk genotype for development of COPD.

We further analyzed the association between each variant and COPD risk based on three genetic models (Table 4). Four susceptibility SNPs were identified have close correlation with COPD risk under recessive model after the adjustment. The "GG" genotype of rs2043055 and rs 187238 were associated with increased risk of COPD (rs2043055: OR $=5.13 ; 95 \%$ CI $=1.12-23.49$; $p=0.021 ;$ rs187238: OR $=4.99 ; 95 \% \mathrm{CI}=1.08-23.06$; $p=0.025)$. Additionally, the "CC" genotype of rs 1946519 was associated with increased risk of COPD $(\mathrm{OR}=2.31$; $95 \% \mathrm{CI}=1.03-5.19 ; p=0.038)$. By contrast, the "TT" genotype of rs 1946518 was associated with decreased risk of COPD $(\mathrm{OR}=0.58 ; 95 \% \mathrm{CI}=0.35-0.98 ; p=0.039)$.

Finally, the relationship of IL18 haplotypes with the risk of developing COPD was also evaluated. Figure 1 showed the linkage disequilibrium (LD) block in IL18 constructed by rs2043055, rs 187238, rs1946518, rs1946519 and rs5744224 in chromosome 11. The association analysis results between different haplotypes and COPD risk was shown in Table 5. However, no haplotype was observed significantly associated with COPD risk after the adjustment.

\section{DISCUSSION}

Previous studies have identified several SNPs associated with COPD; however, the results is still not enough to explain the heredity of COPD. In the present study, we found that the "GG" genotypes of rs2043055 and rs187238, and the "CC" genotype of rs1946519 are significantly associated with increased risk of COPD. Additionally, the "TT" genotype of rs1946518 was associated with decreased risk of COPD. These results shed new light on the genetic predisposition for COPD.

IL-18, a member of the pro-inflammatory cytokine superfamily, is a crucial mediator in immunoreaction in human body. Several SNPs in the promoter region of IL18 have been identified associated with the expression of IL-18. Single nucleotide changes will cause the change of transcription factor binding site [17]. For example, rs $187238(-137 \mathrm{C}>\mathrm{G})$ and $\mathrm{rs} 1946518$ $(-607 \mathrm{C}>\mathrm{A})$ disrupt the H4TF-1 nuclear factor and cAMP-responsive element binding protein binding sites, respectively [18]. The breakdown of transcription factor binding sites will further cause the abnormal immune status in human body. We demonstrated that genetic polymorphisms of IL18 were associated with risk of COPD, which may also due to the abnormal immune status in COPD patients. Based on the above explanation, we speculated that the SNPs in IL18 may cause the abnormal immune status, and further related to the underlying pathogenesis of COPD.

A total of five SNPs were investigated in this study, including rs2043055, rs187238, rs 1946518, rs 1946519 and rs5744224. Among these SNPs, rs2043055 was found to be associated with insulin resistance [19], and risk of chronic chagas disease [20], ischemic stroke [21] and tuberculosis [22]. We for the first time reported that rs2043055 was associated with COPD risk, which need to be confirmed in further study with a larger sample size. Rs187238 and rs1946518 were extensively studied, and identified to have association with several type of disease in different populations, including multiple sclerosis 
Table 1: Characteristics of cases and controls in this study

\begin{tabular}{|c|c|c|c|}
\hline Variables & Case $(N=300)$ & Control $(N=300)$ & $p$-value \\
\hline Sex, No.(\%) & & & $0.806^{\mathrm{a}}$ \\
\hline Male & $153(51)$ & $156(52)$ & \\
\hline Female & $147(49)$ & $144(48)$ & \\
\hline Smoking status & & & $0.865^{\mathrm{a}}$ \\
\hline Smoker & $107(35.7)$ & $105(35.0)$ & \\
\hline Nonsmoker & $193(64.3)$ & $195(65.0)$ & \\
\hline Mean age \pm SD & $69.55 \pm 9.84$ & $68.13 \pm 10.05$ & $0.586^{\mathrm{b}}$ \\
\hline \multicolumn{4}{|l|}{ FEV1\% stage } \\
\hline Mild (more than $80 \%$ ) & $23(7.7)$ & & \\
\hline Moderate $(50 \%-80 \%)$ & $172(57.3)$ & & \\
\hline Severe $(30 \%-50 \%)$ & $93(31.0)$ & & \\
\hline Very severe (less than $30 \%$ ) & $12(4.0)$ & & \\
\hline
\end{tabular}

${ }^{a} p$ value was calculated from Pearson's chi-square tests.

${ }^{\mathrm{b}} p$ value was calculated by Welch's $t$-tests.

Table 2: Allele frequencies in cases and controls and odds ratio estimates for COPD

\begin{tabular}{|c|c|c|c|c|c|c|c|c|c|}
\hline \multirow{2}{*}{ SNP ID } & \multirow{2}{*}{ Gene } & \multirow{2}{*}{ Band } & \multirow{2}{*}{ Position } & \multirow{2}{*}{ Alleles A/B } & \multirow{2}{*}{$p$-HWE } & \multicolumn{2}{|c|}{ MAF } & \multirow{2}{*}{$p$} & \multirow{2}{*}{ OR(95\% CI) } \\
\hline & & & & & & Case & Control & & \\
\hline rs2043055 & IL18 & $11 \mathrm{q} 23.1$ & 112160901 & $\mathrm{G} / \mathrm{A}$ & 0.232 & 0.158 & 0.138 & 0.330 & $1.172(0.851-1.612)$ \\
\hline rs 187238 & IL18 & $11 \mathrm{q} 23.1$ & 112164265 & $\mathrm{G} / \mathrm{C}$ & 0.232 & 0.160 & 0.138 & 0.292 & $1.186(0.863-1.631)$ \\
\hline rs 1946518 & IL18 & $11 \mathrm{q} 23.1$ & 112164735 & $\mathrm{~T} / \mathrm{G}$ & 0.336 & 0.355 & 0.406 & 0.069 & $0.804(0.636-1.016)$ \\
\hline rs1946519 & IL18 & $11 \mathrm{q} 23.1$ & 112164735 & $\mathrm{C} / \mathrm{A}$ & 0.349 & 0.222 & 0.188 & 0.153 & $1.227(0.927-1.626)$ \\
\hline rs5744224 & IL18 & $11 \mathrm{q} 23.1$ & 112164936 & $\mathrm{~T} / \mathrm{A}$ & 0.399 & 0.355 & 0.403 & 0.089 & $0.816(0.646-1.032)$ \\
\hline
\end{tabular}

SNP: single nucleotide polymorphism, Alleles A/B: Minor/major alleles; MAF, minor allele frequency; OR: odds ratio, CI: confidence interval, HWE: Hardy-Weinberg equilibrium

$P$ values were calculated using two-sided Chi-squared test and adjusted by gender, age and smoking status

${ }^{*} p \leq 0.05$ indicates statistical significance

[10], alopecia areata [23], hepatocellular carcinoma [24], chronic hepatitis and cirrhosis [25], recurrent miscarriage [26], coronary artery disease [27], type I diabetes [28], tuberculosis [11] and asthma [13]. It is noteworthy that the $\mathrm{C}$ allele of rs1946518 has been found associated with 1.48-fold increased risk of COPD in male smokers [29]. We found the "CC" genotype of rs1946519 was associated with 2.31-fold increased risk of COPD, which is consistent with previous results. Little information is found about rs1946519 and rs5744224, these two SNPs were only found to be associated with risk of cervical cancer in Chinese literature. In our study, we found the "TT" genotype of rs1946518 was associated with decreased risk of COPD, which suggested this SNP is an important susceptibility locus for disease and need to be confirmed in further studies.

Some limitations should to be considered in our study. First, all the samples were recruited from a same hospital, which may not represent the common population. Second, COPD is a complex genetic disease and influenced by a range of genes. In addition to the five SNPs we investigated, other SNPs may also influence the development of COPD. Therefore, the results identified here need to be further confirmed in a large sample size and different populations.

In sum, the current data showed that IL18 polymorphisms have close correlation with COPD risk in a Chinese Han population. Further studies will focus 
Table 3: Genotypes frequencies of the SNPs and their associations with risk of COPD

\begin{tabular}{|c|c|c|c|c|c|c|c|}
\hline \multirow{2}{*}{ SNP ID } & \multirow{2}{*}{ Genotype } & \multicolumn{2}{|c|}{ Genotype frequencies } & \multicolumn{2}{|c|}{ Without adjustment } & \multicolumn{2}{|c|}{ With adjustment } \\
\hline & & Case & Control & OR $(95 \%$ CI $)$ & $P^{a}$ & OR $(95 \%$ CI $)$ & $P^{b}$ \\
\hline \multirow[t]{3}{*}{ rs 2043055} & $\mathrm{AA}$ & $214(71.3 \%)$ & $220(73.3 \%)$ & 1.00 & & 1.00 & \\
\hline & $\mathrm{AG}$ & $77(25.7 \%)$ & $77(25.7 \%)$ & $1.03(0.71-1.48)$ & 0.200 & $1.12(0.74-1.70)$ & $0.006^{*}$ \\
\hline & GG & $9(3 \%)$ & $3(1 \%)$ & $3.08(0.82-11.55)$ & & $5.29(1.15-24.35)$ & \\
\hline \multirow[t]{3}{*}{ rs 187238} & $\mathrm{CC}$ & $213(71 \%)$ & $220(73.3 \%)$ & 1.00 & & 1.00 & \\
\hline & CG & $78(26 \%)$ & $77(25.7 \%)$ & $1.05(0.72-1.51)$ & 0.200 & $1.13(0.74-1.71)$ & 0.068 \\
\hline & GG & $9(3 \%)$ & $3(1 \%)$ & $3.10(0.83-11.60)$ & & $5.15(1.11-23.96)$ & \\
\hline \multirow[t]{3}{*}{ rs 1946518} & GG & $124(41.5 \%)$ & $109(36.7 \%)$ & 1.00 & & 1.00 & \\
\hline & GT & $138(46.1 \%)$ & $135(45.5 \%)$ & $0.90(0.63-1.28)$ & 0.150 & $0.90(0.60-1.34)$ & 0.100 \\
\hline & TT & $37(12.4 \%)$ & $53(17.9 \%)$ & $0.61(0.38-1.00)$ & & $0.55(0.31-0.96)$ & \\
\hline \multirow[t]{3}{*}{ rs 1946519} & AA & $191(63.7 \%)$ & $200(66.7 \%)$ & 1.00 & & 1.00 & \\
\hline & $\mathrm{AC}$ & $85(28.3 \%)$ & $87(29 \%)$ & $1.02(0.71-1.46)$ & 0.170 & $1.11(0.74-1.66)$ & 0.100 \\
\hline & $\mathrm{CC}$ & $24(8 \%)$ & $13(4.3 \%)$ & $1.93(0.96-3.91)$ & & $2.38(1.05-5.41)$ & \\
\hline \multirow[t]{3}{*}{ rs5744224 } & AA & $124(41.3 \%)$ & $110(36.9 \%)$ & 1.00 & & 1.00 & \\
\hline & $\mathrm{AT}$ & $139(46.3 \%)$ & $136(45.6 \%)$ & $0.91(0.64-1.29)$ & 0.180 & $0.90(0.61-1.35)$ & 0.140 \\
\hline & $\mathrm{TT}$ & $37(12.3 \%)$ & $52(17.4 \%)$ & $0.63(0.39-1.03)$ & & $0.57(0.33-1.00)$ & \\
\hline
\end{tabular}

SNP: Single nucleotide polymorphism; OR: odds ratio; $95 \% \mathrm{CI}$ : 95\% confidence interval.

$\mathrm{P}$ values were calculated by unconditional logistic regression analysis with adjustments for age and gender.

${ }^{*} p \leq 0.05$ indicates statistical significance.

Table 4: Association between SNPs and risk of COPD in multiple inheritance models (adjusted by gender, age and smoking status)

\begin{tabular}{|c|c|c|c|c|c|c|c|c|c|c|c|c|}
\hline \multirow{2}{*}{ SNP ID } & \multirow{2}{*}{ Model } & \multirow{2}{*}{ Genotype } & \multirow{2}{*}{ Control } & \multirow{2}{*}{ Case } & \multicolumn{4}{|c|}{ Without adjustment } & \multicolumn{4}{|c|}{ With adjustment } \\
\hline & & & & & OR $(95 \% \mathrm{CI})$ & $P$-value & AIC & BIC & OR $(95 \% \mathrm{CI})$ & $P$-value & AIC & BIC \\
\hline \multirow{3}{*}{ rs 2043055} & Dominant & $\begin{array}{c}\text { A/A } \\
\text { A/G-G/G }\end{array}$ & $\begin{array}{c}220(73.3 \%) \\
80(26.7 \%)\end{array}$ & $\begin{array}{c}214(71.3 \%) \\
86(28.7 \%)\end{array}$ & $\begin{array}{c}1 \\
1.11(0.77-1.58)\end{array}$ & 0.58 & 835.5 & 844.3 & $\begin{array}{c}1 \\
1.24(0.83-1.86)\end{array}$ & 0.3 & 688 & 705.6 \\
\hline & Recessive & $\begin{array}{c}\mathrm{A} / \mathrm{A}-\mathrm{A} / \mathrm{G} \\
\mathrm{G} / \mathrm{G}\end{array}$ & $\begin{array}{c}297(99 \%) \\
3(1 \%)\end{array}$ & $\begin{array}{c}291(97 \%) \\
9(3 \%)\end{array}$ & $\begin{array}{c}1 \\
3.06(0.82-11.42)\end{array}$ & 0.074 & 832.6 & 841.4 & $\begin{array}{c}1 \\
5.13(1.12-23.49)\end{array}$ & $0.021^{*}$ & 683.7 & 701.3 \\
\hline & Log-additive & - & - & - & $1.17(0.85-1.62)$ & 0.33 & 834.8 & 843.6 & $1.34(0.93-1.93)$ & 0.12 & 686.6 & 704.2 \\
\hline \multirow{3}{*}{ rs 187238} & Dominant & $\begin{array}{c}\mathrm{C} / \mathrm{C} \\
\mathrm{C} / \mathrm{G}-\mathrm{G} / \mathrm{G}\end{array}$ & $\begin{array}{c}220(73.3 \%) \\
80(26.7 \%)\end{array}$ & $\begin{array}{l}213(71 \%) \\
87(29 \%)\end{array}$ & $\begin{array}{c}1 \\
1.12(0.79-1.61)\end{array}$ & 0.52 & 835.4 & 844.2 & $\begin{array}{c}1 \\
1.25(0.83-1.87)\end{array}$ & 0.29 & 688 & 705.5 \\
\hline & Recessive & $\begin{array}{c}\mathrm{C} / \mathrm{C}-\mathrm{C} / \mathrm{G} \\
\mathrm{G} / \mathrm{G}\end{array}$ & $\begin{array}{c}297(99 \%) \\
3(1 \%)\end{array}$ & $\begin{array}{c}291(97 \%) \\
9(3 \%)\end{array}$ & $\begin{array}{c}1 \\
3.06(0.82-11.42)\end{array}$ & 0.074 & 832.6 & 841.4 & $\begin{array}{c}1 \\
4.99(1.08-23.06)\end{array}$ & $0.025^{*}$ & 684 & 701.6 \\
\hline & Log-additive & - & - & - & $1.19(0.86-1.64)$ & 0.29 & 834.6 & 843.4 & $1.34(0.93-1.93)$ & 0.12 & 686.6 & 704.2 \\
\hline & Dominant & $\begin{array}{c}\mathrm{G} / \mathrm{G} \\
\mathrm{G} / \mathrm{T}-\mathrm{T} / \mathrm{T}\end{array}$ & $\begin{array}{l}109(36.7 \%) \\
188(63.3 \%)\end{array}$ & $\begin{array}{l}124(41.5 \%) \\
175(58.5 \%)\end{array}$ & $\begin{array}{c}1 \\
0.82(0.59-1.14)\end{array}$ & 0.23 & 828.8 & 837.6 & $\begin{array}{c}1 \\
0.79(0.54-1.16)\end{array}$ & 0.23 & 682.4 & 700 \\
\hline rs 1946518 & Recessive & $\begin{array}{c}\text { G/G-G/T } \\
\mathrm{T} / \mathrm{T}\end{array}$ & $\begin{array}{c}244(82.2 \%) \\
53(17.9 \%)\end{array}$ & $\begin{array}{c}262(87.6 \%) \\
37(12.4 \%)\end{array}$ & $\begin{array}{c}1 \\
0.65(0.41-1.02)\end{array}$ & 0.062 & 826.7 & 835.5 & $\begin{array}{c}1 \\
0.58(0.35-0.98)\end{array}$ & $0.039^{*}$ & 679.6 & 697.2 \\
\hline & Log-additive & - & - & - & $0.81(0.64-1.02)$ & 0.072 & 827 & 835.8 & $0.77(0.59-1.01)$ & 0.056 & 680.2 & 697.8 \\
\hline & Dominant & $\begin{array}{c}\mathrm{A} / \mathrm{A} \\
\mathrm{A} / \mathrm{C}-\mathrm{C} / \mathrm{C}\end{array}$ & $\begin{array}{l}200(66.7 \%) \\
100(33.3 \%)\end{array}$ & $\begin{array}{l}191(63.7 \%) \\
109(36.3 \%)\end{array}$ & $\begin{array}{c}1 \\
1.14(0.82-1.60)\end{array}$ & 0.44 & 835.2 & 844 & $\begin{array}{c}1 \\
1.26(0.86-1.84)\end{array}$ & 0.24 & 687.7 & 705.3 \\
\hline rs 1946519 & Recessive & $\begin{array}{c}\mathrm{A} / \mathrm{A}-\mathrm{A} / \mathrm{C} \\
\mathrm{C} / \mathrm{C}\end{array}$ & $\begin{array}{c}287(95.7 \%) \\
13(4.3 \%)\end{array}$ & $\begin{array}{c}276(92 \%) \\
24(8 \%)\end{array}$ & $\begin{array}{c}1 \\
1.92(0.96-3.85)\end{array}$ & 0.06 & 832.2 & 841 & $\begin{array}{c}1 \\
2.31(1.03-5.19)\end{array}$ & $0.038^{*}$ & 684.8 & 702.3 \\
\hline & Log-additive & - & - & - & $1.20(0.92-1.57)$ & 0.18 & 833.9 & 842.7 & $1.31(0.96-1.78)$ & 0.082 & 686.1 & 703.6 \\
\hline & Dominant & $\begin{array}{c}\mathrm{A} / \mathrm{A} \\
\mathrm{A} / \mathrm{T}-\mathrm{T} / \mathrm{T}\end{array}$ & $\begin{array}{l}110(36.9 \%) \\
188(63.1 \%)\end{array}$ & $\begin{array}{l}124(41.3 \%) \\
176(58.7 \%)\end{array}$ & $\begin{array}{c}1 \\
0.83(0.60-1.15)\end{array}$ & 0.27 & 831.8 & 840.6 & $\begin{array}{c}1 \\
0.81(0.56-1.18)\end{array}$ & 0.27 & 685.6 & 703.1 \\
\hline rs5744224 & Recessive & $\begin{array}{c}\mathrm{A} / \mathrm{A}-\mathrm{A} / \mathrm{T} \\
\mathrm{T} / \mathrm{T}\end{array}$ & $\begin{array}{c}246(82.5 \%) \\
52(17.4 \%)\end{array}$ & $\begin{array}{c}263(87.7 \%) \\
37(12.3 \%)\end{array}$ & $\begin{array}{c}1 \\
0.67(0.42-1.05)\end{array}$ & 0.078 & 829.9 & 838.7 & $\begin{array}{c}1 \\
0.60(0.36-1.01)\end{array}$ & 0.054 & 683.1 & 700.6 \\
\hline & Log-additive & - & - & - & $0.82(0.65-1.03)$ & 0.093 & 830.2 & 839 & $0.79(0.60-1.03)$ & 0.076 & 683.7 & 701.2 \\
\hline
\end{tabular}

ORs, odds ratios; CI: confidence interval; AIC: Akaike's Information criterion; BIC: Bayesian Information criterion.

${ }^{*} p$ value $\leq 0.05$ indicates statistical significance. 
on the verification of the association in other populations, and the functional role of these SNPs in the development of COPD.

\section{MATERIALS AND METHODS}

\section{Study participants}

For the current analysis, we established a casecontrol study of 300 COPD patients and 300 healthy controls. The diagnosis of COPD was confirmed according to the criteria established by the National Heart, Lung and Blood Institute/World Health Organization Global Initiative for Chronic Obstructive Lung Disease (GOLD) [1]. The entry criteria for COPD cases were post-bronchodilator forced expiratory volume in 1 second (FEV1) less than $80 \%$ predicted and FEV1/forced vital capacity less than $70 \%$. The control group was randomly selected healthy individuals, which included current or ex-smoker with no known disease, no history of any lung disease, and no airflow limitation. All participants in our study were recruited between September 2013 and
September 2016 at Xi'an Hospital of Traditional Chinese Medicine, People's Republic of China.

All of the participants provided written informed consent. The Human Research Committee for Approval of Research Involving Human Subjects, Xi'an Hospital of Traditional Chinese Medicine, approved the use of human blood samples in this study.

\section{SNP selection and genotyping}

In this study, five SNPs in IL18 were selected from previous study for analysis $[18,19,30]$. The lower frequency alleles were coded as the minor allele. All of the SNPs had minor allele frequencies (MAFs) $>5 \%$ in the HapMap Chinese Han Beijing population. Genomic DNA was isolated from whole blood samples using the GoldMag-Mini Purification Kit (GoldMagCo. Ltd. Xi'an, China), and DNA concentrations were measured using the NanoDrop2000 (Thermo Scientific, Waltham, Massachusetts, USA). Sequenom Massarray Assay Design 3.0 softwarewas used to design a multiplexed SNP Mass EXTENDED assay [31-33]. Genotyping was performed

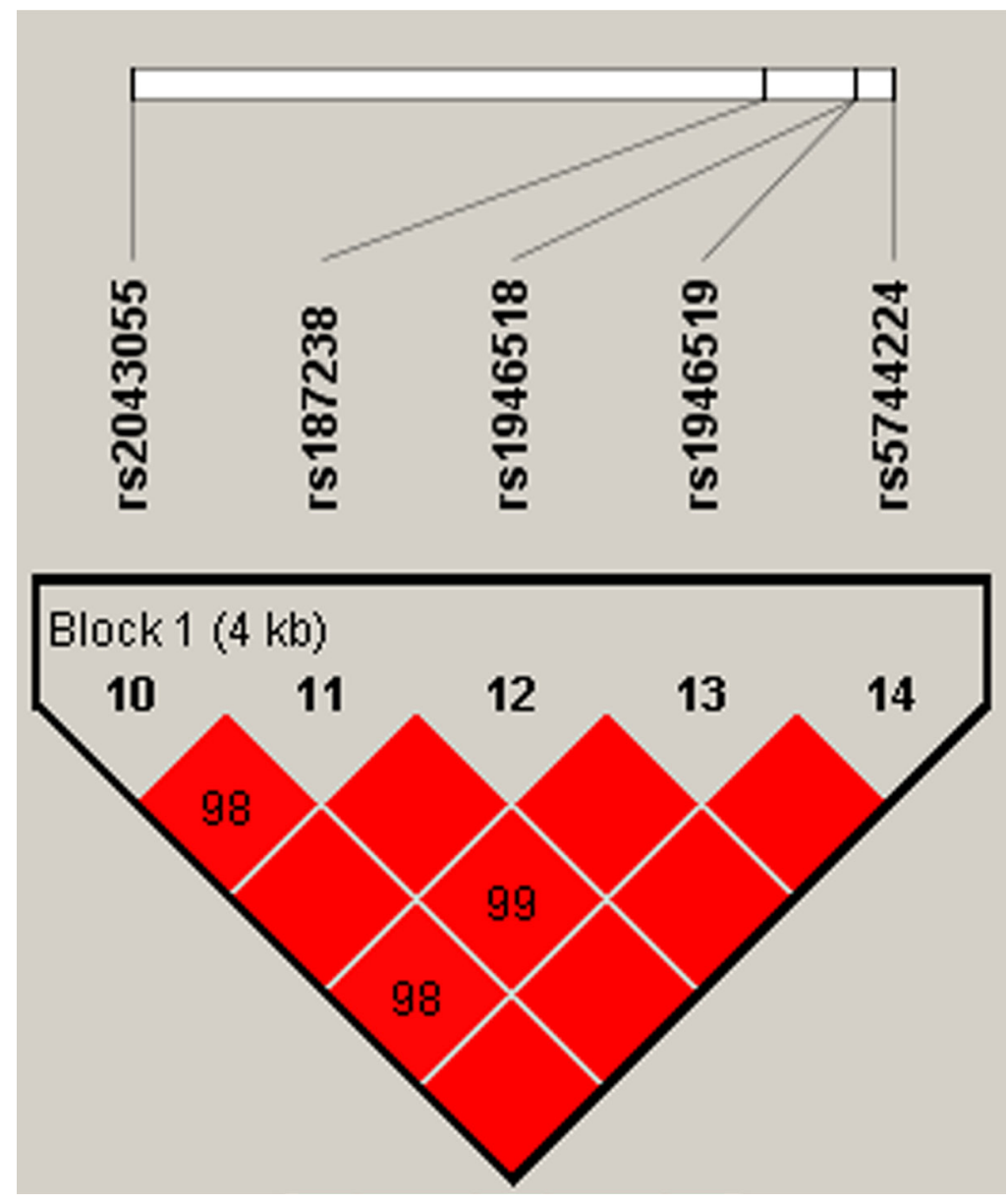

Figure 1: D' linkage map for the five SNPs in IL18. The linkage disequilibrium (LD) block was constructed by rs2043055, rs187238, rs1946518, rs1946519 and rs5744224. 
Table 5: Haplotype frequencies of SNPs in the IL18 gene and the association with COPD risk in case and control subjects

\begin{tabular}{|c|c|c|c|c|c|c|c|c|c|c|}
\hline \multirow{2}{*}{ rs2043055 } & \multirow{2}{*}{ rs187238 } & \multirow{2}{*}{ rs1946518 } & \multirow{2}{*}{ rs1946519 } & \multirow{2}{*}{ rs5744224 } & \multirow{2}{*}{$\begin{array}{l}\text { Freq } \\
\text { (case) }\end{array}$} & \multirow{2}{*}{$\begin{array}{c}\text { Freq } \\
\text { (control) }\end{array}$} & \multicolumn{2}{|c|}{ Without adjustment } & \multicolumn{2}{|c|}{ With adjustment } \\
\hline & & & & & & & OR $(95 \%$ CI $)$ & $P$-value & OR $(95 \%$ CI) & $P$-value \\
\hline A & $\mathrm{C}$ & G & A & A & 0.420 & 0.407 & 1 & - & 1 & - \\
\hline A & $\mathrm{C}$ & $\mathrm{T}$ & A & $\mathrm{T}$ & 0.355 & 0.402 & $0.85(0.66-1.10)$ & 0.22 & $0.84(0.63-1.12)$ & 0.24 \\
\hline G & G & G & $\mathrm{C}$ & A & 0.156 & 0.138 & $1.08(0.77-1.52)$ & 0.67 & $1.22(0.82-1.79)$ & 0.32 \\
\hline A & $\mathrm{C}$ & $\mathrm{G}$ & $\mathrm{C}$ & $\mathrm{A}$ & 0.064 & 0.050 & $1.16(0.71-1.88)$ & 0.55 & $1.18(0.66-2.10)$ & 0.58 \\
\hline
\end{tabular}

$p$ values were calculated from two-sided Chi-squared test/Fisher's exact test, and adjusted by gender, age and smoking status;

${ }^{*} p \leq 0.05$ indicates statistical significance.

on a Sequenom MassARRAY RS1000 platform using the manufacturer's protocol. Data management and analysis was performed using the Sequenom Typer 4.0 Software $[34,35]$.

\section{Statistical analysis}

We used Microsoft Excel (Microsoft Corporation, Redmond, WA, USA) and the SPSS 21.0 statistical package (SPSS, Chicago, IL, USA) to perform statistical analyses. All $p$ values presented in this study were two sided, and $p=0.05$ was considered the cutoff for statistical significance. Differences in the characteristics of the case and control study populations were analyzed using chi-square tests for categorical variables and Welch's t tests for continuous variables. In all analyses, the lower frequency allele was considered to be the 'risk' allele. Control genotype frequencies for each SNP were tested for departure from HWE using Fisher's exact tests. Allele and genotype frequencies in the cases and controls were compared using chi-square tests [36]. Three genetic models (dominant, recessive and log-additive) were used to assess the association between each genotype and the risk of COPD. The effects of the polymorphisms on the risk of COPD were expressed as odds ratios (ORs) with 95\% confidence interval (CIs), which were calculated using unconditional logistic regression analysis after adjusting for gender, age and smoking status [37]. Akaike's Information Criterion (AIC) and Bayesian Information Criterion (BIC) are calculated to select the best model for a specific SNP.

Haploview software version 4.2 was used to analyze the association between haplotypes and the COPD. Linkage disequilibrium (LD) analysis was performed using genotype data from all the subjects. The pattern of LD was analyzed using two parameters, $\mathrm{r}^{2}$ and D'. Statistical significance was established when $p<0.05$.

\section{CONFLICTS OF INTEREST}

The authors have no conflicts of interest to report.

\section{REFERENCES}

1. Vestbo J, Hurd SS, Agusti AG, Jones PW, Vogelmeier C, Anzueto A, Barnes PJ, Fabbri LM, Martinez FJ, Nishimura M, Stockley RA, Sin DD, Rodriguez-Roisin R. Global strategy for the diagnosis, management, and prevention of chronic obstructive pulmonary disease: GOLD executive summary. Am J Respir Crit Care Med. 2013; 187:347-65. https://doi.org/10.1164/rccm.201204-0596PP.

2. Lokke A, Lange P, Scharling H, Fabricius P, Vestbo J. Developing COPD: a 25 year follow up study of the general population. Thorax. 2006; 61:935-9. https://doi. org/10.1136/thx.2006.062802.

3. Silverman EK, Vestbo J, Agusti A, Anderson W, Bakke PS, Barnes KC, Barr RG, Bleecker ER, Boezen HM, Burkart KM, Celli BR, Cho MH, Cookson WO, et al. Opportunities and challenges in the genetics of COPD 2010: an International COPD Genetics Conference report. COPD. 2011; 8:121-35. https://doi.org/10.3109/15412555.2011.5 58864 .

4. Pillai SG, Ge D, Zhu G, Kong X, Shianna KV, Need AC, Feng S, Hersh CP, Bakke P, Gulsvik A. A Genome-Wide Association Study in Chronic Obstructive Pulmonary Disease (COPD): Identification of Two Major Susceptibility Loci. Plos Genetics. 2009; 5:e1000421.

5. Kim DK, Cho MH, Hersh CP, Lomas DA, Miller BE, Kong X, Bakke P, Gulsvik A, Agustí A, Wouters E. Genomewide association analysis of blood biomarkers in chronic obstructive pulmonary disease. American Journal of Respiratory \& Critical Care Medicine. 2012; 186:1238-47.

6. Ding Y, Yang D, Zhou L, Xu J, Chen Y, He P, Yao J, Chen J, Niu H, Sun P. Variants in multiple genes polymorphism association analysis of COPD in the Chinese Li population. Int J Chron Obstruct Pulmon Dis. 2015; 10:1455-63.

7. Dinarello CA, Daniela N, Soohyun K, Gilles K. Interleukin-18 and IL-18 Binding Protein. Frontiers in Immunology. 2013; 4:289.

8. Nakanishi $\mathrm{K}$, Yoshimoto $\mathrm{T}$, Tsutsui $\mathrm{H}$, Okamura $\mathrm{H}$. Interleukin-18 regulates both $\mathrm{Th} 1$ and $\mathrm{Th} 2$ responses. Annual Review of Immunology. 2001; 19:423.

9. Fujibayashi Y, Fujimori Y, Kasumoto I, Kai S, Hara $\mathrm{H}$, Okamura H, Tsutsui H, Ogawa H, Nakanishi K. 
Interleukin-18 regulates $\mathrm{T}$ helper 1 or 2 immune responses of human cord blood CD4+ V alpha $24+\mathrm{V}$ beta $11+$ natural killer T cells. International Journal of Molecular Medicine. 2007; 20:241.

10. Karakas CS, Öz ZS, Dursun A, Unal A, Emre U, Cicek S, Keni FM. Interleukin 18 gene polymorphism is a risk factor for multiple sclerosis. Molecular Biology Reports. 2014; 41:1653-8.

11. Lee SH, Choi IH, Jeon YK, Park SJ, Lee HK, Lee YM, Chang CL, Kim YS, Lee MK, Park SK. Association between the interleukin-18 promoter polymorphism and pulmonary tuberculosis in a Korean population. International Journal of Tuberculosis \& Lung Disease. 2011; 15:1246.

12. Dai ZJ, Liu XH, Wang M, Guo Y, Zhu W, Li X, Lin S, Tian T, Liu K, Zheng Y. IL-18 polymorphisms contribute to hepatitis B virus-related cirrhosis and hepatocellular carcinoma susceptibility in Chinese population: a casecontrol study. Oncotarget. 2017; 8:81350-81360. https:// doi.org/10.18632/oncotarget.18531.

13. Ma Y, Zhang B, Tang RK, Liu Y, Peng GG. Interleukin-18 promoter polymorphism and asthma risk: a meta-analysis. Molecular Biology Reports. 2012; 39:1371-6.

14. Back LK, Farias TD, Da CP, Muniz YC, Ribeiro MC, Fernandes BL, Fernandes CK, de Souza IR. Functional polymorphisms of interleukin-18 gene and risk of breast cancer in a Brazilian population. Tissue Antigens. 2014; $84: 229$.

15. Gao SJ, Li Z, Wei L, Lu W, Lei C, Zhen Z, Zhu HH. Interleukin-18 genetic polymorphisms contributedifferentially to the susceptibility to Crohn's disease. World Journal of Gastroenterology. 2015; 21:8711-22.

16. Farjadfar A, Mojtahedi Z, Ghayumi MA, Erfani N, Haghshenas MR, Ghaderi A. Interleukin-18 promoter polymorphism is associated with lung cancer: A casecontrol study. Acta Oncologica. 2009; 48:971.

17. Al-Khateeb GM, Sater MS, Finan RR, Mustafa FE, Al-Busaidi AS, Al-Sulaiti MA, Almawi WY. Analysis of interleukin-18 promoter polymorphisms and changes in interleukin-18 serum levels underscores the involvement of interleukin-18 in recurrent spontaneous miscarriage. Fertility \& Sterility. 2011; 96:921.

18. Giedraitis V, He B, Huang WX, Hillert J. Cloning and mutation analysis of the human IL-18 promoter: a possible role of polymorphisms in expression regulation. Journal of Neuroimmunology. 2001; 112:146.

19. Smart MC, Dedoussis G, Yiannakouris N, Grisoni ML, Dror GK, Yannakoulia M, Papoutsakis C, Louizou E, Mantzoros CS, Melistas L. Genetic variation within IL18 is associated with insulin levels, insulin resistance and postprandial measures. Nutrition Metabolism \& Cardiovascular Diseases. 2011; 21:476.

20. Nogueira LG, Frade AF, Ianni BM, Laugier L, Pissetti CW, Cabantous S, Baron M, Peixoto Gde L, Borges Ade M, Donadi E, Marin-Neto JA, Schmidt A, Dias F, et al.
Functional IL18 polymorphism and susceptibility to Chronic Chagas Disease. Cytokine. 2015; 73:79-83.

21. Bis JC, Heckbert SR, Smith NL, Reiner AP, Rice K, Lumley T, Hindorff L, Marciante KD, Enquobahrie D, Monks SA. Variation in inflammation-related genes and risk of incident nonfatal myocardial infarction or ischemic stroke. Atherosclerosis. 2008; 198:166-73.

22. Hall NB, Igo RP, Malone LSL, Truitt B, Schnell A, Tao L, Okware B, Nsereko M, Chervenak K, Lancioni C. Polymorphisms in TICAM2 and IL1B are associated with TB. Genes \& Immunity. 2015; 16:127-33.

23. Su KK, Park HJ, Chung JH, Kim JW, Seok H, Lew BL, Sim WY. Association Between Interleukin 18 Polymorphisms and Alopecia Areata in Koreans. Journal of Interferon \& Cytokine Research. 2014; 34:349-53.

24. Zhu SL, Zhao Y, Hu XY, Luo T, Chen ZS, Zhang Y, Yang SH, Zhou L, Li LQ. Genetic polymorphisms -137 (rs187238) and -607 (rs1946518) in the interleukin-18 promoter may not be associated with development of hepatocellular carcinoma. Sci Rep. 2016; 6:39404.

25. Yalcin S, Demirbas S, Onguru O. Investigation of interleukin-18 polymorphism in hepatit B virus carriers, chronic hepatitis and cirrhosis patients. Journal of Experimental \& Integrative Medicine. 2014; 4:175.

26. Yue J, Tong Y, Xie L, Ma T, Yang J. Genetic variant in IL-33 is associated with idiopathic recurrent miscarriage in Chinese Han population. International Journal of Molecular Sciences. 2015; 16:4180-9.

27. Dong LP, Li JM, Luo WQ, Tang L, Yuan H, Liu GL, Zhang $\mathrm{XD}$, Li GY, Bao MH. Meta-analysis of the association between IL-18 rs1946518, rs187238 polymorphisms and coronary artery diseases. International Journal of Clinical and Experimental Medicine. 2017; 10:1891-1899.

28. Al-Lahham Y, Akb M, Souza EM, Alberton D, Fgm R, Valdameri G, Picheth G. Interleukin-18 (rs187238) and glucose transporter 4 (rs5435) polymorphisms in EuroBrazilians with type 1 diabetes. Genetics and molecular research. 2017; 16.

29. Wang J, Liu X, Xie J, Xu Y. Association of interleukin-18 promoter polymorphisms with chronic obstructive pulmonary disease in male smokers. International Journal of Immunogenetics. 2013; 40:204-8.

30. Yang HL, Pin BH, Wang Q, Zheng L, Tang W, Qi T, Bao J. [Association of interleukin-18 gene rs1946519 and rs360718 single nucleotide polymorphism with cervical cancer]. [Article in Chinese]. Journal of Southern Medical University. 2007; 27:1006.

31. Gabriel S, Ziaugra L, Tabbaa D. SNP genotyping using the Sequenom MassARRAY iPLEX platform. Curr Protoc Hum Genet. 2009; Chapter 2:Unit 2.12. https://doi. org/10.1002/0471142905.hg0212s60.

32. Kochl S, Niederstatter H, Parson W. DNA extraction and quantitation of forensic samples using the 
phenol-chloroform method and real-time PCR. Methods Mol Biol. 2005; 297:13-30.

33. Trembizki E, Smith H, Lahra MM, Chen M, Donovan B, Fairley CK, Guy R, Kaldor J, Regan D, Ward J, Nissen MD, Sloots TP, Whiley DM. High-throughput informative single nucleotide polymorphism-based typing of Neisseria gonorrhoeae using the Sequenom MassARRAY iPLEX platform. J Antimicrob Chemother. 2014; 69:1526-32. https://doi.org/10.1093/jac/dkt544.

34. Gabriel S, Ziaugra L, Tabbaa D. SNP genotyping using the Sequenom MassARRAY iPLEX platform. Current protocols in human genetics. 2009; Chapter 2:Unit 2.12.
35. Thomas RK, Baker AC, DeBiasi RM, Winckler W, LaFramboise T, Lin WM, Wang M, Feng W, Zander T, MacConaill LE. High-throughput oncogene mutation profiling in human cancer. Nature genetics. 2007; 39:347-51.

36. Adamec C. [Example of the use of the nonparametric test. Test X2 for comparison of 2 independent examples]. [Article in Czech]. Ceskoslovenské zdravotnictví. 1964; 12:613.

37. Bland JM, Altman DG. Statistics notes. The odds ratio. BMJ. 2000; 320:1468. 